\title{
Free Radicals, Salicylic Acid and Mycotoxins in Asparagus After Inoculation with Fusarium proliferatum and $F$. oxysporum
}

\author{
Bernadeta Dobosz • Kinga Drzewiecka • Agnieszka Waskiewicz • \\ Lidia Irzykowska • Jan Bocianowski - Zbigniew Karolewski • \\ Marian Kostecki • Zdzislaw Kruczynski • Ryszard Krzyminiewski • \\ Zbigniew Weber • Piotr Golinski
}

Received: 26 November 2010/Revised: 17 March 2011/Published online: 9 June 2011

(C) The Author(s) 2011. This article is published with open access at Springerlink.com

\begin{abstract}
Electron paramagnetic resonance was used to monitor free radicals and paramagnetic species like $\mathrm{Fe}, \mathrm{Mn}, \mathrm{Cu}$ generation, stability and status in Asparagus officinalis infected by common pathogens Fusarium proliferatum and $F$. oxysporum. Occurrence of $F$. proliferatum and $F$. oxysporum, level of free radicals and other paramagnetic species, as well as salicylic acid and mycotoxins content in roots and stems of seedlings were estimated on the second and fourth week after inoculation. In the first term free and total salicylic acid contents were related to free radicals level in stem $\left(P=0.010\right.$ and $P=0.033$, respectively). Concentration of $\mathrm{Fe}^{3+}$ ions in porphyrin complexes $(g=2.3, g=2.9)$ was related to the species of pathogen. There was no significant difference between $\mathrm{Mn}^{2+}$ concentrations in stem samples; however, the level of free radicals in samples inoculated with $F$. proliferatum was significantly higher when compared to $F$. oxysporum.
\end{abstract}

B. Dobosz $(\bowtie) \cdot$ Z. Kruczynski · R. Krzyminiewski

Medical Physics Division, Faculty of Physics, Adam Mickiewicz University,

Umultowska 85, 61-614 Poznan, Poland

e-mail: benia@amu.edu.pl

K. Drzewiecka · A. Waskiewicz · M. Kostecki · P. Golinski

Department of Chemistry, Poznan University of Life Sciences,

Wojska Polskiego 75, 60-625 Poznan, Poland

L. Irzykowska $\cdot$ Z. Karolewski $\cdot$ Z. Weber

Department of Phytopathology, Poznan University of Life Sciences,

Dabrowskiego 159, 60-594 Poznan, Poland

J. Bocianowski

Department of Mathematical and Statistical Methods,

Poznan University of Life Sciences, Wojska Polskiego 28, 60-637 Poznan, Poland 


\section{Introduction}

Asparagus officinalis L. is a popular worldwide vegetable. F. proliferatum (Matsushima) Nirenberg and $F$. oxysporum (Schlechtend) are the most common pathogens of asparagus causing crown and root rot [1-5]. These fungi are also known as microorganisms responsible for the oxidative stress induction in plants, what might be explained by salicylic acid biosynthesis and accumulation and free radicals formation.

Electron paramagnetic resonance (EPR) is a technique capable of direct detection of free radicals and is successfully used in free radicals and paramagnetic species like $\mathrm{Fe}, \mathrm{Mn}, \mathrm{Cu}$ generation, stability and status monitoring [6]. Reactive oxygen species (ROS) initiate the peroxidation of lipids in plant cells. Essentially membrane lipids peroxidation involves three distinct stages, including initiation, progression and termination. Initiation involves transition metal complexes-especially those of $\mathrm{Fe}$ or $\mathrm{Cu}$-and an activated oxygen complex. These compounds can abstract allylic hydrogens or act as a catalyst in the decomposition of existing in the tissue lipid hydro-peroxides [7].

Manganese is a nutritionally essential microelement for metabolism in all living organisms and is required as a redox cofactor and/or an activator in many enzymes, such as manganese superoxide dismutase (MnSOD), ribonucleic acid (RNA) polymerases, and isocitrate dehydrogenase $[6,8]$. In plants, Mn plays a critical role as an accumulator of positive charge equivalents in the light-induced oxidation of water by photosystem II (PS II) [9-11]. Mn deficiency in plants is indicated by leaf discoloration and impacts freezing tolerance, reproductive fitness, and carbohydrate metabolism. The bioavailability of manganese depends on its oxidation state. The bivalent cation $\mathrm{Mn}^{2+}$ only can be absorbed by plants, while the higher oxidation states are not accessible in plant metabolism. The mechanisms of Mn acquisition and the control of its homeostasis are poorly understood [12]. It is well known that $\mathrm{Mn}^{2+}$ and $\mathrm{Fe}^{2+}$ share the same entry route in plants. Iron uptake by roots is probably regulated by the activity of a plasma membrane redox system which reduces $\mathrm{Fe}^{3+}$ from various $\mathrm{Fe}^{3+}$-chelates to ferrous ion $\mathrm{Fe}^{2+}$ [13]. Fe is involved in chlorophyll metabolism and is also a component of many enzymes associated with energy transfer, nitrogen reduction and fixation, and lignin formation. Fe is associated with sulfur in plants to form compounds that catalyze other reactions. Fe deficiency in plants causes decrease of dry weight, number of ribosomes, salt and protein nitrogen contents and increases contents of amino and organic acids.

The interaction between plants and pathogens induces the immune response involving the biosynthesis of salicylic acid (SA). In cells, the compound plays a regulatory role in plant resistance to stress factors responsible for such oxidative stress as pathogens, ozone, xenobiotics, heavy metals, etc. [14-17]. In plants, salicylic acid is observed in form of free unbounded molecules (SA) and bounded forms including methyl-salicylates (MeSA), glucoside esters (SAG) and amino acid conjugates of the compound [18]. The potential role of salicylic acid in asparagus resistance to $F$. oxysporum f.sp. asparagi (Foa) induction was described by $\mathrm{He}$ and Wolyn [19].

$F$. proliferatum and $F$. oxysporum, well known pathogens of asparagus, are able to form mycotoxins (moniliformin and fumonisins), secondary metabolites with 
well-documented health hazard to humans and animals [20, 21]. Among fumonisins, fumonisin $\mathrm{B}_{1}\left(\mathrm{FB}_{1}\right)$ is most frequently detected in nature at the highest concentrations and is recognized as a risk factor for esophageal [22] and liver cancers [23], neural tube defects [24] and cardiovascular problems [25] in human populations consuming relatively large amounts of food prepared on the basis of contaminated maize. Available toxicological evidence forced the International Agency for Research on Cancer (IARC) to classify in $2002 \mathrm{FB}_{1}$ as a compound possibly carcinogenic to humans (class $2 \mathrm{~B}$ carcinogen) [26]. Moniliformin (MON) exhibits cytotoxic and cardiotoxic activity, causes developmental disorders and may also induce the progress of Keshan's disease [27]. Tolerable concentrations of some mycotoxins in food, feed and their components are officially regulated in several countries [28].

The aim of this study was to elucidate the plant-pathogen interaction between asparagus and their pathogens ( $F$. proliferatum and $F$. oxysporum). The EPR spectroscopy was used as a tool to evaluate the impact of the infection by both the Fusarium species on the level of free radicals and other paramagnetic species in asparagus with an attempt to correlate the above observation with concentration of mycotoxins and salicylic acid in inoculated plants.

\section{Materials and Methods}

In a greenhouse experiment, 1-year-old asparagus seedlings cv. 'Andreas' were grown in pots with steamed soil. Seeds were previously disinfected with $5 \%$ suspension of Benlate fungicide in acetone. Wounded parts of plants were inoculated with $5 \mathrm{~mm}$ disks of potato dextrose agar (PDA) medium overgrown by one of the four tested single spore isolates: F. proliferatum (06-76sb or 06-94s) and $F$. oxysporum (07-25wz or 07-32s). Isolates of $F$. proliferatum were of asparagus origin (spears cv. Eposs, grown in Swidwowiec_-100 km West of Poznan, Poland), while F. oxysporum strains were isolated from spears collected at Poznan farmers market. Store roots of seven different seedlings were inoculated with each of tested isolates separately, while noninoculated asparagus seedlings were used as a control group. Occurrence of $F$. proliferatum or $F$. oxysporum, the level of free radicals or other paramagnetic species, as well as salicylic acid and mycotoxin contents in roots and stems of seedlings were estimated on the second (first term) and fourth (second term) week after inoculation (in triplicates).

\subsection{Evaluation of $F$. proliferatum and $F$. oxysporum Occurrence in Asparagus Seedlings}

Stems and roots of all asparagus seedlings were tested for $F$. proliferatum and $F$. oxysporum presence followed by isolation of the fungi on PDA medium. Colonies of the growing fungi were transferred onto standard media and identified according to the methods described by Booth [29], Gerlach and Nirenberg [30], Kwasna et al. [31], and Barnett and Hunter [32]. 


\subsection{EPR Measurements}

The free radicals concentration as well as the type of paramagnetic species in root and stem samples of asparagus plants were determined using EPR method. The EPR measurements were performed on a Bruker EPR EMX-10 X-band $(9.4 \mathrm{GHz})$ spectrometer with magnetic field second modulation frequency of $100 \mathrm{kHz}$. The samples were prepared as described in Sect. 2. They were stored in a Dewar with liquid nitrogen and EPR spectra were recorded at temperature of 77 $K$. The first-derivative spectra were recorded using magnetic field scan range width of 10 and $600 \mathrm{mT}$ and amplitudes of the second modulation were 0.3 up to $1 \mathrm{mT}$. The values of the microwave power were adjusted to obtain nonsaturated and nonbroadened EPR spectra for the spectral components. The amplifications of the spectrometer were adjusted to the intensities of EPR signals and were changed in a range from $1 \times 10^{4}$ to $1 \times 10^{5}$. The standard weak pitch sample with concentration of free radicals equal to $2 \times 10^{13}$ spins was used to determine the concentration of free radicals in samples. The concentration of free radicals was calculated from integrated intensity of free radical signals with $g$ factor $g=2.0035$ and was about $10^{15}$ spins in the samples. The accuracy of the concentration determination was about $13 \%$. The concentration of spins was calculated per gram of sample.

\subsection{Chemical Analysis}

Sodium dihydrophosphate, potassium hydroxide, acetic acid, $n$-hexane, $o$ phosphoric acid were purchased from POCh (Gliwice, Poland). Fumonisin B $\mathrm{B}_{1}$, moniliformin and salicylic acid standards were purchased with standard grade certificate from Sigma-Aldrich (Steinheim, Germany). Organic solvents of highperformance liquid chromatography (HPLC) grade, disodium tetraborate, 2-mercaptoethanol and $t$-butyl-ammonium hydroxide, sodium acetate and all other chemicals were also purchased from Sigma-Aldrich. Water for the HPLC mobile phase preparation was purified using a Milli-Q system (Milipore, Bedford, MA, USA).

\subsection{Analysis of Salicylic Acid Content in Asparagus Spears}

Salicylic acid in free form (SA), as well as that conjugated as a glucoside (SAG), and total salicylic acid (TSA) were determined by HPLC according to the method recommended by Yalpani et al. [33]. A Waters Co. chromatograph with software (Milford, MA, USA), composed of 2699 Alliance separation module and 2475 multi- $\lambda$ fluorescence detector, was used. Chromatographic separation was performed on a Spherisorb ODS2 Waters Co. column $(3 \mu \mathrm{m}, 4.6 \times 10 \mathrm{~mm})$. The content of salicylic acid released from its glucoside was calculated as the difference between assays without and with glucoside enzymatic degradation (SAG = TSA - SA). Furthermore, the percent of SA in TSA content was calculated and labeled as SA $\%$. 
2.5 Analysis of Mycotoxins in Asparagus Spears

\subsubsection{Fumonisin $B_{1}$}

Fumonisin $\mathrm{B}_{1}$ was extracted from plant material with methanol:water ratio of $3: 1$ $\mathrm{v} / \mathrm{v}$ according to the method described by Shepard et al. [34].

Before HPLC analysis, the extracts were evaporated to dryness reconstituted in methanol $(200 \mu \mathrm{l})$ and aliquots derivatized with $o$-phthaldialdehyde. A Waters 2695 apparatus (Waters Co., Milford, MA, USA) with a C-18 Nova Pak column $(3.9 \times 150 \mathrm{~mm})$ and a Waters 2475 fluorescence detector $\left(\lambda_{\mathrm{Ex}}=335 \mathrm{~nm}\right.$ and $\lambda_{\mathrm{Em}}=440 \mathrm{~nm}$ ) were used to quantify the metabolite. Methanol-sodium dihydrophosphate $(0.1 \mathrm{M}$ in water) solution $(77: 23, \mathrm{v} / \mathrm{v})$ adjusted to $\mathrm{pH} 3.35$ with $o$-phosphoric acid was used as the mobile phase. Recovery for $\mathrm{FB}_{1}$ was $89 \%$ (estimated in triplicates by the mycotoxin extraction from blank samples spiked with $10-100 \mathrm{ng} \mathrm{g}^{-1}$ of the compound). The relative standard deviation was lower than $8 \%$.

\subsubsection{Moniliformin}

Moniliformin was extracted from plant material with acetonitrile:methanol:water ratio of 16:3:1 v/v/v using $5 \mathrm{ml}$ of solvent per $1 \mathrm{~g}$ of sample. Extracts were defatted with $n$-hexane $(3 \times 50 \mathrm{ml})$, then concentrated and purified on a Florisil column according to the method described by Kostecki et al. [35].

Moniliformin was quantified by HPLC using a Waters 501 apparatus (Waters Co., Milford, MA, USA) with a C-18 Nova Pak column $(3.9 \times 300 \mathrm{~mm})$ and a Waters $486 \mathrm{UV}$ detector $\left(\lambda_{\max }=229 \mathrm{~nm}\right.$ for MON). MON was eluted from the column with acetonitrile:water ratio of $15: 85 \mathrm{v} / \mathrm{v}$ buffered with $10 \mathrm{ml}$ of $0.1 \mathrm{M}$ $\mathrm{K}_{2} \mathrm{HPO}_{4}$ in $40 \% t$-butyl-ammonium hydroxide in 11 of solvent [36]. Recovery for MON was $90 \%$, and the relative standard deviation was below $7 \%$.

\subsection{Statistical Analysis}

The two-way analysis of variance of results of two terms of harvest was carried out to determine the effects of isolates, parts of plants and the isolates $\times$ parts of plants interaction on the variability of the level of free radicals. The least significant differences for each trait were calculated. The associations between free radical levels and other characteristics were estimated using analysis of regression. Analysis of the data was performed using the statistical package GenStat v. 7.1 [37].

\section{Results}

Analysis of variance indicated that the main effect of part of the plant was significant $(P<0.001)$ for the level of free radicals $(\mathrm{FR})$ in the second term. The exemplary EPR spectra of free radicals and other paramagnetic species are shown in Figs. 1, 2, 3, and 4. 

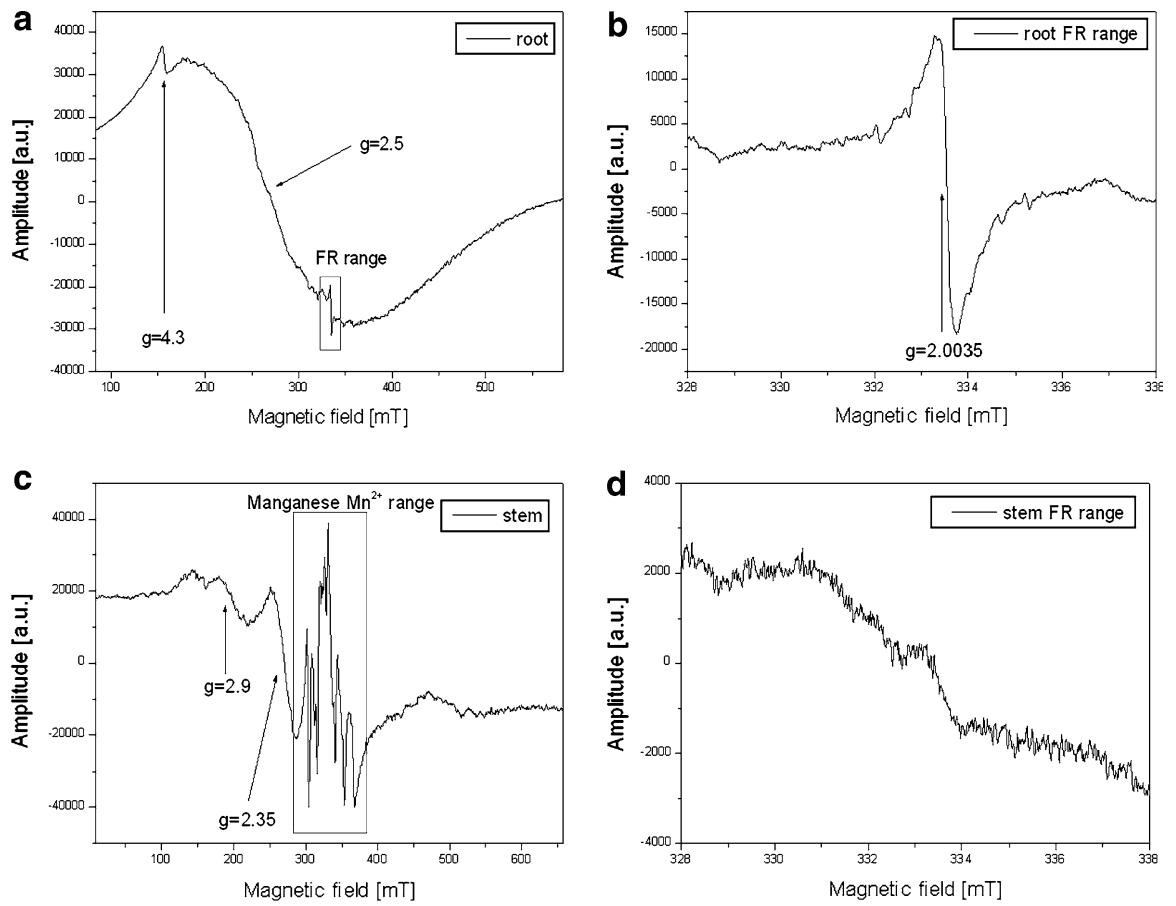

Fig. 1 EPR spectra of asparagus root $(\mathbf{a}, \mathbf{b})$ and stem $(\mathbf{c}, \mathbf{d})$ inoculated with $F$. proliferatum (isolate $06-76 \mathrm{sb})$. FR free radical range

EPR spectra were recorded in the range of $600 \mathrm{mT}$ (Figs. 1, 2, 3a, c) or in the range of free radicals of $10 \mathrm{mT}$ (Figs. 1, 2, 3b, d) and/or additional spectra of manganese $\left(\mathrm{Mn}^{2+}\right)$ ions were recorded when needed (Fig. 4).

For all samples the concentration of FR and paramagnetic centers like manganese $\mathrm{Mn}^{2+}$ and/or iron $\mathrm{Fe}^{3+}$ were determined. The intensities of free radicals EPR signals and of paramagnetic species (manganese and iron) are shown in Tables 1 and 2, respectively. For root samples, the EPR signals of FR had similar spectroscopic parameters, i.e., $g=2.0035 \pm 0.0005$ and $\Delta B=0.8 \pm 0.03 \mathrm{mT}$ (Figs. 1, 2, 3b) and in the whole range of magnetic fields, the EPR signals of $\mathrm{Fe}^{3+}$ with $g=4.3$ were also observed (Figs. 1, 2, 3a). In contrary to roots, in stem samples the EPR lines of $\mathrm{Mn}^{2+}$ were observed depending on Fusarium species and isolate (Figs. 1, 2c).

In the first term ( 2 weeks after inoculation) the concentration of free salicylic acid (SA) and TSA was correlated with the FR level in stem $(P=0.010$ and $P=0.033$, respectively) (Table 3 ). Additionally, $F$. proliferatum occurrence in root was correlated with the FR level in stem $(P<0.001)$. Accumulation in roots of MON as well as $\mathrm{FB}_{1}$ and MON simultaneously influenced the FR level in stem at significance level $P=0.011$ and $P=0.018$, respectively. Furthermore, the relations between SA, TSA in root and FR concentration in stem were found ( $P=0.015$ and $P=0.022$, respectively). In the second term (4 weeks after inoculation) only one relationship between $F$. proliferatum occurrence and FR level 

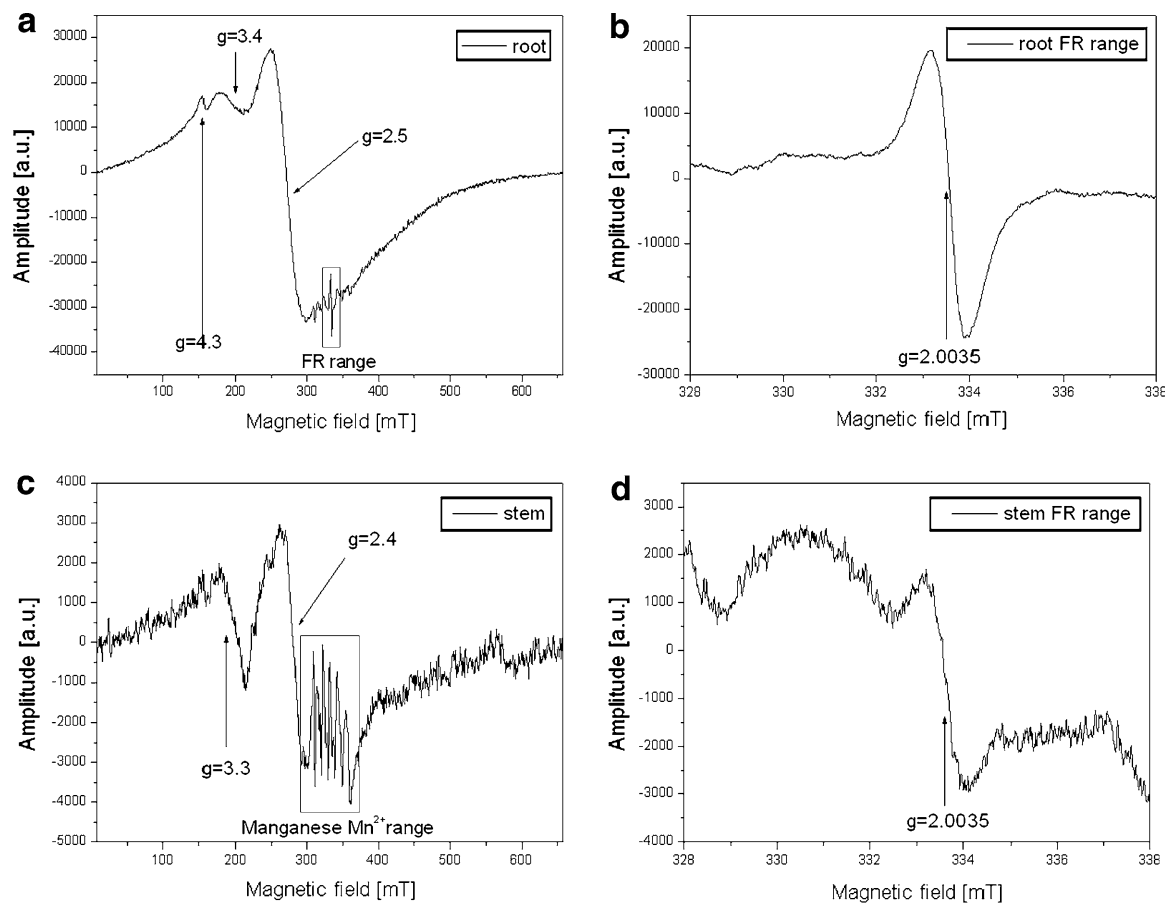

Fig. 2 EPR spectra of asparagus root $(\mathbf{a}, \mathbf{b})$ and stem $(\mathbf{c}, \mathbf{d})$ inoculated with $F$. oxysporum (isolate 07-32s). FR free radical range

$(P=0.002)$ was observed for stem (Table 4). We have also observed significant influence of MON and simultaneously $\mathrm{FB}_{1}$ and $\mathrm{MON}$ concentration in root on the FR level in stem $(P<0.001$ and $P=0.005$, respectively).

\section{Discussion}

Both series (terms) of EPR analysis for roots and stems exhibited similarities in paramagnetic ions and free radical concentrations (Figs. 1, 2, 3). Results presented in Table 1 indicate that in roots the level of free radicals was more than tenfold higher when compared to stems. Differences in spectroscopic parameters and characteristics of radical lines $(g=2.0035 \pm 0.0005$ and $\Delta B=0.8 \pm 0.03 \mathrm{mT})$ were not significant for radicals generated in roots and stems, which suggests the same type of FR in both types of the samples.

Relatively low value of $g$ spectroscopic factor $(g<2.004)$ suggests carboncentered radical with a nearby oxygen atom that effects in $g$-factor increase when compared with typical pure carbon-centered radicals. Contrary to our results, typical oxygen-centered radicals have higher $g$-factor $(g>2.004)$ [38, 39]. Oxygencentered radicals are well known and reported in elucidation pathogenesis of several diseases, but it is also possible that carbon-centered radicals, being reactive to cells, 

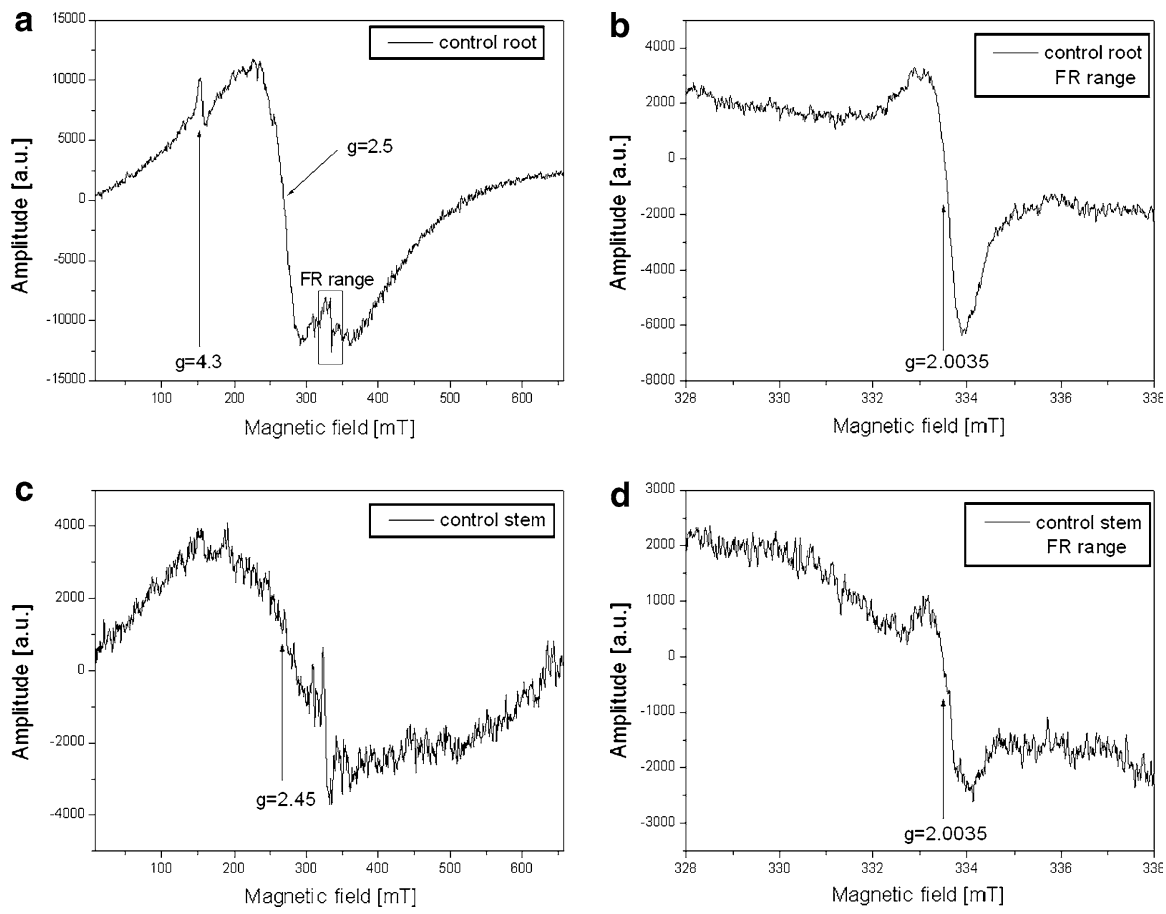

Fig. 3 EPR spectra of control (noninoculated) asparagus root $(\mathbf{a}, \mathbf{b})$, stem $(\mathbf{c}, \mathbf{d})$. $F R$ free radical range

play an important role in biochemistry of inflammation stages. Significantly higher concentrations of free radicals in roots than in stems were probably due to the inoculation site (roots) and relatively slow penetration of the fungus into the stems. Since the second series of samples, collected 4 weeks after inoculation, showed significant decrease in the free radical content when compared to the first series (Table 1). High concentration of free radicals just after the inoculation was probably the consequence of short time after the injury. It is worth noticing that both concentrations and spectroscopic parameters of inorganic paramagnetic ions indicate interesting relations between the type of sample and isolate of fungal pathogen used for inoculation. In root samples, the high level of $\mathrm{Fe}^{3+}$ ions was responsible for both EPR lines $g=4.3$ and $g=2.3-2.5$ (Figs. 1, 2, 3a). On the contrary, in stems, $\mathrm{Mn}^{2+}$ ions only responsible for specific six lines in the EPR spectrum were observed with no EPR $g=4.3$ lines (Figs. 1, 2c, 4). Organic $\mathrm{Fe}^{3+}$ complexes with orthorhombic symmetry were responsible for $g=4.3 \mathrm{EPR}$ signals [40]. The EPR signals of $\mathrm{Fe}^{3+}$ ions $(g=2.3, g=2.9)$ might be correlated with different ferromagnetic aggregates formed in plant tissue upon decomposition of iron-containing proteins and enzymes or with iron ions in porphyrin complexes [41]. These signals were related to the species of pathogen. High $\mathrm{Fe}^{3+}$ concentration was observed in stems of plants inoculated with $F$. proliferatum (Table 2). There was no significant difference between $\mathrm{Mn}^{2+}$ concentrations in stem samples; however, the 

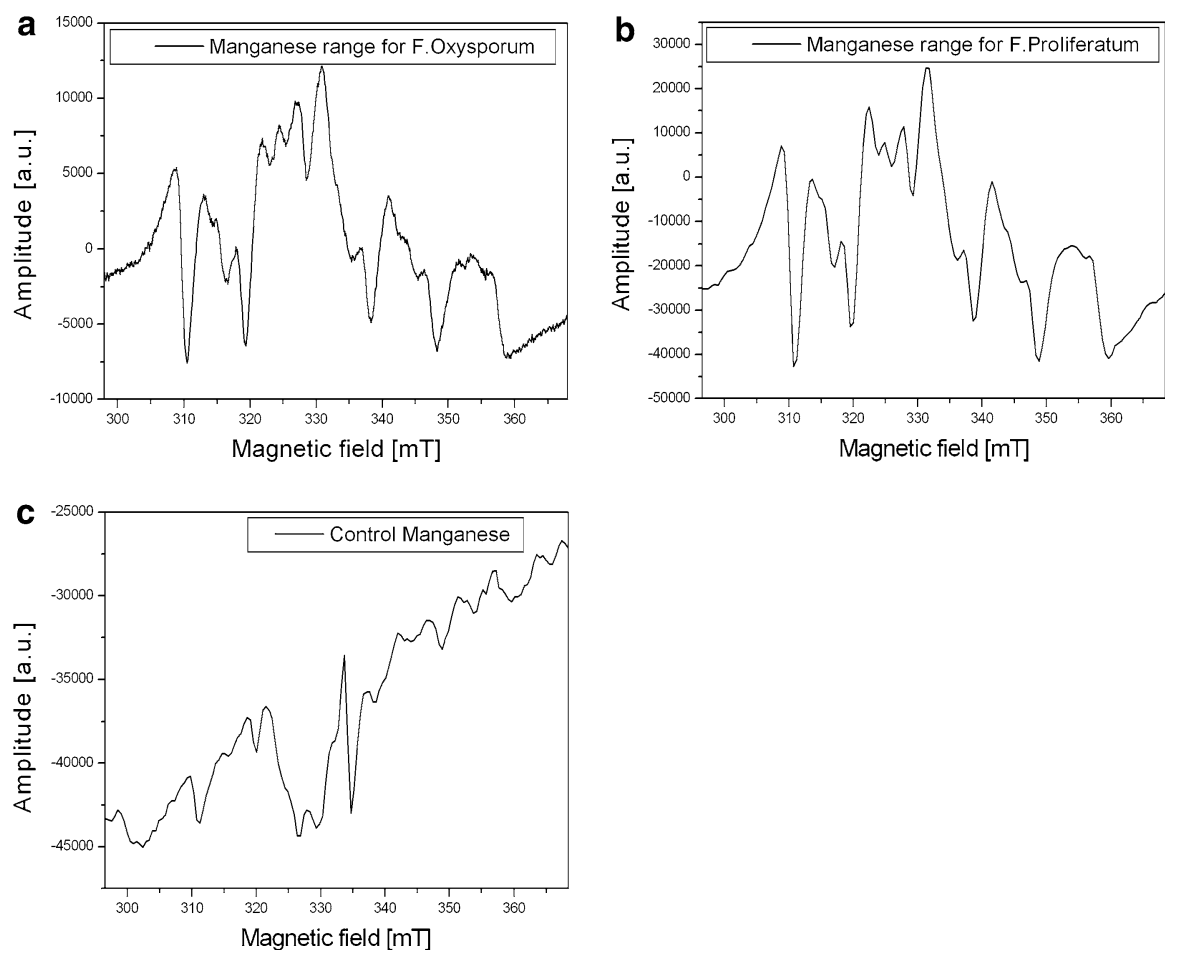

Fig. 4 EPR spectrum of manganese in stem sample: a inoculated with $F$. oxysporum (isolate 07-32s); b inoculated with $F$. proliferatum (isolate 06-76sb); c control sample

Table 1 Mean values of free radicals level $\left(\times 10^{15} \mathrm{spins} / \mathrm{g}\right)$ in parts of asparagus plant

\begin{tabular}{|c|c|c|c|c|c|}
\hline \multirow[t]{2}{*}{ Isolate } & & \multicolumn{2}{|c|}{ First term ( 2 weeks after inoculation) } & \multicolumn{2}{|c|}{ Second term ( 4 weeks after inoculation) } \\
\hline & & Root & Stem & Root & Stem \\
\hline F. $o$ & $07-25 w z$ & 315.2 & 0 & 227.3 & 48.5 \\
\hline F. $o$ & $07-32 s$ & 393.9 & 0 & 200 & 42.4 \\
\hline$F \cdot p$ & $06-76 \mathrm{sb}$ & $2,115.2$ & 57.6 & 203 & 75.8 \\
\hline$F \cdot p$ & $06-94 s$ & 154.5 & 54.5 & 112.1 & 57.6 \\
\hline Control & & 136.4 & 36.4 & 163.6 & 27.3 \\
\hline- & $\mathrm{LSD}_{0.05}$ & $1,430.2$ & & 197.2 & \\
\hline
\end{tabular}

level of free radicals in samples inoculated with $F$. proliferatum was significantly higher when compared to $F$. oxysporum, suggesting that inoculating pathogen influenced the formation and concentration of both generated free radicals and complexes of $\mathrm{Fe}^{3+}$ ions in stems.

It is also interesting to compare the concentration of free radicals and inorganic complexes with the level of salicylic acid in the studied asparagus plants inoculated with the fungi. Samples with higher FR concentration in stems (isolate 06-76sb and 
Table 2 Concentration of iron $\left(\mathrm{Fe}^{3+}\right)$ and manganese $\left(\mathrm{Mn}^{2+}\right)$ paramagnetic species in stem samples in the first term

\begin{tabular}{|c|c|c|c|c|c|}
\hline Isolate & & $\begin{array}{l}g=4.3 \\
\mathrm{Fe}^{3+}\end{array}$ & $\begin{array}{l}g=2.9 \\
\mathrm{Fe}^{3+}\end{array}$ & $\begin{array}{l}g=2.3-2.5 \\
\mathrm{Fe}^{3+}\end{array}$ & First line of $\mathrm{Mn}^{2+}$ \\
\hline F. o. & $07-25 w z$ & Trace & - & - & $339,272.7$ \\
\hline F. o. & $07-32 \mathrm{~s}$ & - & - & - & $404,424.2$ \\
\hline F. p. & $06-76 \mathrm{sb}$ & - & $211,878.8$ & $584,787.9$ & $524,575.8$ \\
\hline F. p. & $06-94 \mathrm{~s}$ & Trace & $308,212.1$ & - & 305,000 \\
\hline Control & & - & - & $100,309.1$ & $139,969.7$ \\
\hline
\end{tabular}

Table 3 Trends between the analyzed traits of samples collected in the first term

\begin{tabular}{lllll}
\hline $\begin{array}{l}\text { Response } \\
\text { variable }\end{array}$ & $\begin{array}{l}\text { Explanatory } \\
\text { variable }\end{array}$ & $\begin{array}{l}\text { Estimates of regression } \\
\text { coefficients }\end{array}$ & $P$ value & $\begin{array}{l}\text { Percentage variation } \\
\text { accounted }\end{array}$ \\
\hline $\begin{array}{l}\text { In stem } \\
\text { FR }\end{array}$ & SA & 0.050 & 0.010 & 38.7 \\
FR & TSA & 0.001 & 0.033 & 26.9 \\
\hline Stem & Root & & & \\
\hline FR & F. p. & 1.534 & $<0.001$ & 61.1 \\
FR & MON & 0.006 & 0.011 & 40.7 \\
FR & SA & 0.091 & 0.015 & 37.6 \\
FR & TSA & 0.065 & 0.022 & 33.6 \\
FR & FB ${ }_{1} ;$ MON & $0.090 ; 0.006$ & 0.018 & 46.4 \\
\hline
\end{tabular}

$F R$ free radicals, F. p. Fusarium proliferatum, $S A$ free salicylic acid, TSA total salicylic acid, $F B_{1}$ fumonisin $\mathrm{B}_{1}, M O N$ moniliformin

Table 4 Trends between the analyzed traits in samples collected in the second term

\begin{tabular}{lllll}
\hline $\begin{array}{l}\text { Response } \\
\text { variable }\end{array}$ & $\begin{array}{l}\text { Explanatory } \\
\text { variable }\end{array}$ & $\begin{array}{l}\text { Estimates of regression } \\
\text { coefficients }\end{array}$ & $P$ value & $\begin{array}{l}\text { Percentage variation } \\
\text { accounted }\end{array}$ \\
\hline $\begin{array}{l}\text { Stem } \\
\text { FR }\end{array}$ & $F . p$. & 2.581 & 0.002 & 51.0 \\
\hline Stem & Root & & & \\
\hline FR & MON & 0.003 & $<0.001$ & 59.2 \\
FR & FB $;$ MON & $-0.005 ; 0.003$ & 0.005 & 55.7 \\
\hline
\end{tabular}

$F R$ free radicals, $F$. p. Fusarium proliferatum, $F B_{1}$ fumonisin $\mathrm{B}_{1}, M O N$ moniliformin

06-94s) contained the higher level of all forms of salicylic acid (SA, SAG, TSA). Another relation between the level of FR and SA in roots of collected samples (I and II term) was also observed (Table 3). In the second term, the reduction of FR, SA 
and SA\% concentration followed by increase of the content of conjugated (biologically inactive) form (SAG) in roots was observed, which is probably due to freshly wounded tissue followed by higher concentration of FR and $\mathrm{Fe}^{3+}$ ions. This observation confirms the results of earlier reports on the model plants under oxidative stress in controlled conditions. Exogenous SA altered hydrogen peroxide metabolism in cells by increase of superoxide dismutase and decrease of catalase and peroxidase activity, thus leading to the accumulation of $\mathrm{H}_{2} \mathrm{O}_{2}$ oxidizing cell constituents followed by apoptosis (cell death) [42, 43].

Free radicals damage lipids in cell membranes, which increases the concentration of $\mathrm{Mn}, \mathrm{Fe}$ and $\mathrm{Cu}$. Since the highest difference in the level of both FR and paramagnetic ions was observed in the first term, the short time after inoculation is the explanation of this phenomenon. Very high concentration of FR in roots of sample 06-76sb can be explained by inoculation with two isolates of two pathogens and probably two different mechanisms of pathogenesis for $F$. oxysporum and F. proliferatum take place.

\section{Conclusions}

It can be concluded that because of infected plants, defensive mechanisms induce the increase of free form of salicylic acid (SA), free radical (FR) concentration, propagation of Fusarium and as a consequence mycotoxins formation.

Acknowledgments This work was supported by the Polish Ministry of Science and Higher Education as the research project nr. NN 310170933.

Open Access This article is distributed under the terms of the Creative Commons Attribution Noncommercial License which permits any noncommercial use, distribution, and reproduction in any medium, provided the original author(s) and source are credited.

\section{References}

1. C. Sadowski, M. Knaflewski, Acta Hortic. 271, 343-351 (1990)

2. W.H. Elmer, D.A. Johnson, G.I. Mink, Plant Dis. 80, 117-125 (1996)

3. M. Gossmann, C. Büttner, G. Bedlan, Pflanzenschutzberichte 59, 45-54 (2001)

4. Z. Weber, M. Kostecki, S. Von Bargen, M. Gossmann, A. Waskiewicz, J. Bocianowski, M. Knaflewski, C. Büttner, P. Goliński, J. Phytopathol. 154, 209-216 (2006)

5. A. Waskiewicz, L. Irzykowska, Z. Karolewski, J. Bocianowski, M. Kostecki, P. Golinski, M. Knaflewski, Z. Weber, Cereal Res. Commun. Suppl. B 36, 405-407 (2008)

6. M.A. Morsy, M.M. Khaled, Spectrochim. Acta Part A 58, 1271-1277 (2002)

7. S. Bhattacharjee, Curr. Sci. 89(7), 1113-1121 (2005)

8. M.D. Allen, J. Kropat, S. Tottey, J.A. Del Campo, S.S. Merchant, Plant Physiol. 143, 263-277 (2007)

9. J. Amesz, Biochim. Biophys. Acta 726, 1-12 (1983)

10. A. Alberti, D. Macciantelli, S. Predieri, F. Rossi, Trees 14, 312-315 (2000)

11. S. Merchant, M.R. Sawaya, Plant Cell 17, 648-663 (2005)

12. T.J.W. Yang, P.J. Perry, S. Cioani, S. Pandian, W. Schmidt, J. Exp. Bot. 59(12), 3453-3464 (2008)

13. R.M. Welch, W.A. Norvell, S.C. Schaefer, J.E. Shaff, L.V. Kochian, Planta 190(4), 555-561 (1993)

14. K. Borowiak, K. Drzewiecka, P. Goliński, J. Zbierska, Electron. J. Pol. Agric. Univ. Environ. Dev. 10(1), \#06 (2007) 
15. N.I. Vasyukova, O.L. Ozeretskovskaya, Appl. Biochem. Microbiol. 43(4), 367-373 (2007)

16. D. Gross, B. Parthier, J. Plant Growth Regul. 13, 93-114 (1994)

17. I. Raskin, Plant Mol. Biol. 43, 439-462 (1992)

18. J.L. Coquoz, A. Buchala, J.P. Métraux, Plant Physiol. 117, 1095-1101 (1998)

19. C.Y. He, D.J. Wolyn, Plant. Pathol. 54, 227-232 (2005)

20. A. Logrieco, B. Dako, A. Moretti, S. Frisullo, A. Visconti, J. Agric. Food Chem. 46, 5201-5204 (1998)

21. W. Seefelder, M. Gossman, H.U. Humpf, J. Agric. Food Chem. 50, 2778-2781 (2002)

22. W.F.O. Marasas, Environ. Health Perspect. 109, 239-243 (2001)

23. Y. Ueno, K. Iijima, S.D. Wang, Y. Sugiura, M. Sekijima, T. Tanaka, C. Chen, S.Z. Yu, Food Chem. Toxicol. 35, 1143-1150 (1997)

24. S.A. Missmer, L. Suarez, M. Felkner, E. Wang, A.H. Merrill Jr., K.J. Rothman, K.A. Hendricks, Environ. Health Perspect. 114, 237-241 (2006)

25. J.E. Fincham, W.F.O. Marasas, J.J. Taljaard, N.P. Kriek, C.J. Badenhorst, W.C. Gelderblom, J.V. Seier, C.M. Smuts, M. Faber, M.J. Weight, Atherosclerosis 94, 13-25 (1992)

26. International Agency for Research on Cancer (IARC), Fumonisin $\mathrm{B}_{1}$, in IARC Monographs on the evaluation of the carcinogenic risks to humans: Some traditional herbal medicines, some mycotoxins, naphthalene and styrene, vol. 82 (IARC, Lyon, 2002), pp. 301-366

27. G. Pineda-Valdes, L.B. Bullerman, J. Food Prot. 63(11), 1598-1601 (2000)

28. Commission of European Communities. Commission recommendation of 17 August, 2006 on the presence of deoxynivalenol, zearalenone, ochratoxin A, T-2 and HT-2 and fumonisins in products intended for animal feeding. Off. J. Eur. Union L229/7; August 232006

29. C. Booth, The genus Fusarium (CABI, Kew, Surrey, 1971), pp. 32-185

30. W. Gerlach, H. Nirenberg, The genus Fusarium. A Pictorial Atlas (Mitt. Biol. Bundesanst. Land. Forstwirtsch., Berlin-Dahlem, 1982), pp. 9-386

31. H. Kwasna, J. Chelkowski, P. Zajkowski, Fungi (Mycota) XXII (Polish Academy of Sciences, Warszawa, Krakow, 1991), pp. 30-111

32. H.L. Barnett, B.B. Hunter, Illustrated Genera of Imperfect Fungi (APS Press, St. Paul, 1998)

33. N. Yalpani, P. Silverman, T.M.A. Wilson, D.A. Kleiler, I. Raskin, Plant Cell 3, 808-818 (1991)

34. G.S. Shepard, E.W. Sydenham, P.G. Thiel, W.F.O. Marasas, J. Liq. Chromatogr. 13, 2077-2087 (1990)

35. M. Kostecki, H. Wisniewska, G. Perrone, A. Ritieni, P. Golinski, J. Chelkowski, A. Logrieco, Food Addit. Contam. 16(9), 361-365 (1999)

36. M. Sharman, J. Gilbert, J. Chełkowski, Food Addit. Contam. 4, 459-466 (1991)

37. R. Payne, D. Murrey, S. Harding, D. Baird, D. Soutou, P. Lane, GenStat for Windows, 7th edition (VSN International, Oxford, 2003)

38. L. Tian, C.P. Koshland, J. Yano, V.K. Yachandra, I.T. Yu, S.C. Lee, D. Lucas, Energy Fuels 23, 2523-2526 (2009)

39. B. Dellinger, S. Lomnicki, L. Khachatryan, Z. Maskos, R.W. Hall, J. Adounkpe, C. McFerrin, C. Truong, Proc. Combust. Inst. 31, 521-528 (2007)

40. I. Muckenschnabel, B.A. Goodman, B. Williamson, G.D. Lyon, N. Deighton, J. Exp. Bot. 53(367), 207-214 (2002)

41. S.C. Tang, S. Koch, G.C. Papaefthymiou, S. Foner, R.B. Frankel, J.A. Ibers, R.H. Holm, J. Am. Chem. Soc. 98(9), 2414-2434 (1976)

42. J. Durner, D. Klessig, J. Biol. Chem. 271, 28492-28501 (1996)

43. M. Rao, G. Paliyath, D. Ormrod, D. Murr, C. Watkins, Plant Physiol. 115, 137-149 (1997) 